Review

\title{
Clinical Significance of Internal Friction Connection and Micro-Threads in Implant-Supported Prostheses: A Literature Review
}

Ki-Won Jeong ${ }^{1,+}$, Jeong Chan Kim ${ }^{2,+}$, In-Sung Luke Yeo ${ }^{3, *}$

1. Department of Prosthodontics, Seoul National University Dental Hospital, Seoul 03080, Korea; EMail: jkw857@gmail.com

2. Private practice, Seoul 03198, Korea; E-Mail: perio kjc@naver.com

3. Department of Prosthodontics, School of Dentistry and Dental Research Institute, Seoul National University, Seoul 03080, Korea; E-Mails: E-mail: pros53@snu.ac.kr

$\dagger$ These authors contributed equally to this work.

* Correspondence: In-Sung Luke Yeo; E-Mail: pros53@snu.ac.kr

Academic Editor: Hossein Hosseinkhani

Special Issue: Research on Dental Materials

Recent Progress in Materials

2020, volume 2 , issue 4

doi:10.21926/rpm.2004024
Received: August 13, 2020

Accepted: December 08, 2020

Published: December 17, 2020

\begin{abstract}
A connection structure using both a screw and friction is advantageous to secure an abutment to an implant. Understanding the biomechanics of the implant-abutment connection is necessary for the long-term clinical survival of a dental implant with decreased complications. The internal conical friction connection structure and micro-threads have shown favorable biological hard tissue response with exceptional structural features. The internal conical connection structure maintains the soft tissue seal and the marginal bone level around the implant. The durability of the implant wall thickness at the top is balanced via micro-threads with the load-transfer mechanism, resulting in proper peri-implant bone strain. These two structural devices are designed to achieve implant-abutment connection stability by redistributing an external load and by minimizing screw loosening events that cause implant component fractures and marginal bone loss.
\end{abstract}

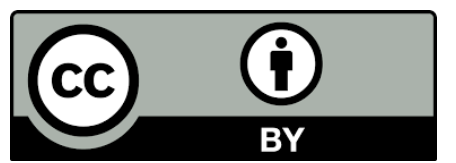

(C) 2020 by the author. This is an open access article distributed under the conditions of the Creative Commons by Attribution License, which permits unrestricted use, distribution, and reproduction in any medium or format, provided the original work is correctly cited. 


\section{Keywords}

Dental implants; implant-abutment connection; alveolar bone loss; prosthesis failure; friction; implantology

\section{Introduction}

In the late 1960s, the emergence of dental implants, introduced by Per-Ingvar Brånemark, proved a milestone in the history of dentistry. Since then, several implants have been introduced, tremendously impacting dental science. Dental implants have significant implications. First, an implant allows a fixed prosthesis in almost every edentulous case that is treated with a removable prosthesis in the past. Thus, it is possible to profoundly improve the comfort of a patient in terms of function, esthetics, and phonetics of an implant [1]. Second, in the case of severe alveolar bone resorption, a removable prosthesis was commonly used in the past, but the use of two or more implants, such as an implant overdenture could offer more stability. In the McGill consensus statement of 2002, the first choice of standard treatment for mandibular edentulous patients was the implant overdenture [2]. Also, an implant can prevent the disuse atrophy of the bone by transferring the occlusal force to the surrounding bone [3]. On the other hand, as dental implants have many different features and biomechanics compared to natural teeth, many complications, such as screw loosening, implant fracture, and bone resorption associated with the implants inevitably may occur [4-8]. These complications are considered to be closely associated with the implant-abutment connection (IAC) [7-9]. Maintaining the stability of the IAC is important for longterm clinical success [10-11]. To prevent complications, the biomechanics of the IAC need closer scrutiny.

Implant systems can be classified by their implant-abutment connections. The systems can be divided according to the connection assemblies: a screw connection, a friction connection, or a screw-friction connection. Bozkaya et al. showed that the Brånemark implant abutment was entirely retained with a screw, and the Bicon implant abutment was solely maintained by friction without a screw [9]. The abutments in many internal connection structures were retained simultaneously by a screw and friction [9].

In order to tightly secure the abutment to the implant, the connection method involving a screw and tapered friction fit system has traditionally been used [9]. For the screw connection system, the connection between the implant and the abutment depends on the screw-preload, which is generated by applying a predetermined amount of torque during installation. The tapered fit provides a wide surface/contact at the implant-abutment interface, which ensures a secure connection with a strong friction. In the screw connection system, screw loosening is one of the most frequent mechanical complications [5]. Screw loosening occurs when the external load exceeds the preload, or creep deformation is observed in the screw-implant interface. However, when a tapered fit is used in the implant-abutment connection, it may decrease the frequency of screw complications [9, 12-13]. The internal conical friction connection between an implant and an abutment, as with the Astra Tech Implant systems (Dentsply Sirona Inc., Charlotte, NC, USA) and Deep Implant System (Deep Implant System, Seongnam, Gyeonggi-do, South Korea), exhibits less screw loosening and bone growth rather than bone resorption [14-19]. This bone gain is an opposite 
phenomenon to the common implant complications occurring in clinical situations. These features are obtained from the biomechanics of two main structures of frictional interfaces and microthreads. It is necessary to investigate these two features, theoretically and experimentally [20].

This review explores the nature of the frictional interface-strictly the internal conical friction connection-and of the micro-thread and investigates the effects of these structures on the bone response to the implant.

\section{Internal Conical Implant-Abutment Friction Connection}

\subsection{Characteristics of Internal Conical Friction Connection}

The conical friction connection between an implant and an abutment was first introduced by the Astra Tech Implant system to solve the loosening problem of an abutment screw, which frequently appeared in the external hex connection used in the original Brånemark implant system. In the internal conical friction connection, the stability of the implant-abutment connection is established not only by the preload applied to the abutment screw but also by the frictional force between the implant and abutment, which is a major contributor to stability. This is also called a friction-screwretained connection [20].

The external hex connection has an almost universal structure and dimension across manufacturers, whereas the internal friction connection is very different in terms of the design and dimension from manufacturer to manufacturer, especially in terms of the contact length (twodimensional) or area (three-dimensional) at the interface between the implant and the abutment [21]. For instance, the Astra Tech Implant system has a different contact length according to the implant diameter. In 1990, there were three-step different connection depths: shallow, regular, and deep connection depths at implant diameters of 3.5, 4.0, and above $4.5 \mathrm{~mm}$, respectively. (see Figure 1). As the implant diameter is increased, the connection depth is deepened by $1.25 \mathrm{~mm}$. This shows that the thickness of the upper implant wall and the degree of taper are kept consistent. The deeper the connection depth, the larger the contact surface between the implant and abutment would be. Bozkaya et al. showed that when the length of the interface between abutment and implant was increased, the stability of the connection was increased in proportion to the fourth power of the contact length [22]. Therefore, it is believed that a deep connection depth with a consistent thickness of implant wall withstands lateral force well. 

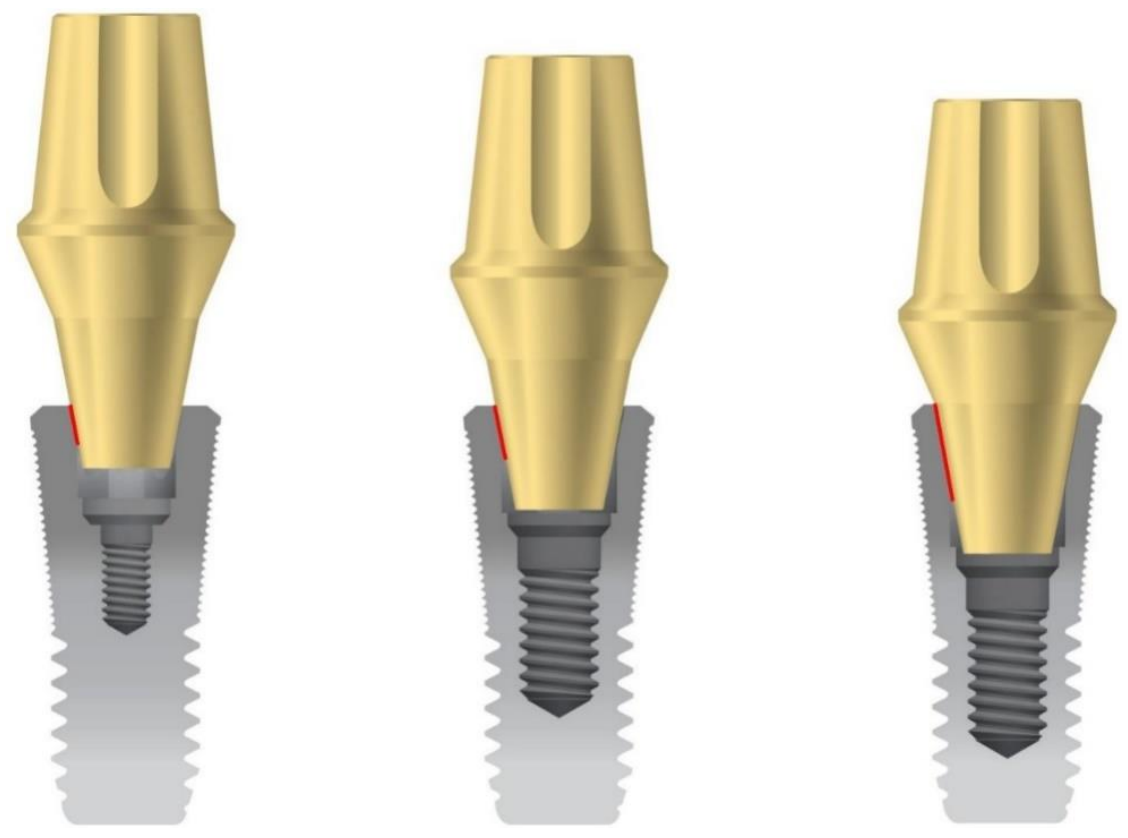

Figure 1 Schematic diagram of a shallow (left), a regular (middle), and a deep (right) connection. Note that the contact length (red lines) is larger in the deep connection than that in the shallow connection. There is no absolute standard to classify the connections into shallow, regular, and deep; however, the important factor is that the larger the contact length is, the more stable the implant-abutment connection would be.

The degree of taper on the inner surface of the implant in contact with the abutment is another important factor in connection stability [22]. If the degree of the taper is increased, the rate of implant fracture gets decreased, but the connection becomes unstable $[9,23]$. Furthermore, the ratio of the contribution of internal friction force to the stability decreases, while that of the screw increases. The internal conical friction connection usually has approximately $11^{\circ}$ of taper, while there are a few connection structures whose taper angles are less than $8^{\circ}[21]$. This $11^{\circ}$ taper is considered to be adequate for optimal clinical results for esthetics and marginal bone resorption, taking into account the emergence profile and bone stimulation [20, 24, 25].

\subsection{Implant-Abutment Connection Stability and Biomechanical Problems}

When an implant diameter is increased while maintaining the same connection depth, the implant wall gets thickened at the top and becomes more resistant to lateral force and implant fracture. Therefore, in the system of a three-step connection with different connection depths, the deeper the connection depth, the thinner the implant wall, indicating easy fracturability of the implant. However, when the connection depth is deepened, the area of the contact surface is increased to induce stress distribution and thereby reduce the chances of an implant fracture [20, 24].

When a lateral force is applied to an implant with the internal conical friction connection structure, the abutment first contacts the upper part of the inner implant wall, and then the upper implant wall is flared due to elasticity $[23,26]$. This enables the movement of the abutment in the apical direction, so the lower part of the implant wall comes into more contact with the abutment, resulting in it receiving most of the lateral force (Figure 2). As the lower implant wall is relatively 
thick, it can endure the external stress well. Therefore, it is necessary to ensure that the preload applied to the abutment screw disappears with the movement of the abutment, such as an abutment sinking and settling effect, so the abutment screw re-tightening should be performed repeatedly until the implant-abutment connection gets stable [27-28]. When the abutment screw is not re-tightened periodically, the screw preload decreases gradually [29]. The friction area in the internal friction connection can prevent connection instability, resulting in peri-implant pocket formation and bone resorption [20]. However, nonadherence to the re-tightening procedure can make the connection unstable resulting in biological failures, such as soft tissue seal breakage and peri-implant bone loss, as well as biomechanical failures, such as the fracture of the components of the abutment and the implant.
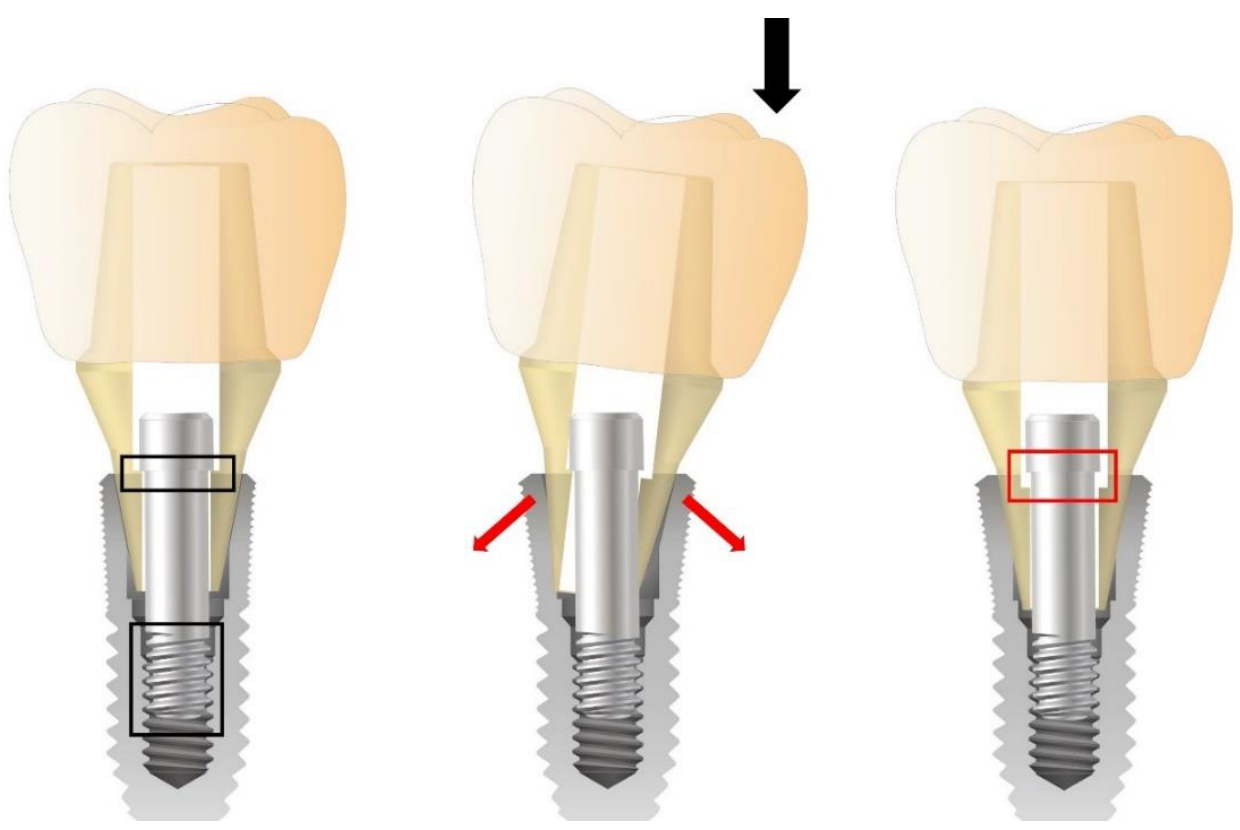

Figure 2 Left figure shows that preload is applied at the head of an abutment screw and between the threads (black rectangles). When the masticatory force is loaded on the implant-supported crown (black arrow), the horizontal vector occurs, and the abutment surface pushes the implant wall. Repetition of this pushing expands the wall (red arrows) in two right abutments, and the abutment sinks. The abutment sinking reduces the screw preload (red rectangle on the right), resulting in screw loosening. Elongation of the abutment screw also occurs.

When the abutment screw is tightened strongly, the preload- the force used to connect strongly between the abutment and implant by the clamping force of the screw-is formed on the abutment screw $[9,28]$. Therefore, the preload should be removed for loosening the screw $[5,30]$. There are several causes for the loss of preload, of which the elongation of the screw is caused by a lateral force exerted on the implant prosthesis [31]. The lateral force makes the upper implant wall flare at the implant-abutment interface and bends the abutment laterally. When the abutment is bent in the lateral direction, the abutment screw is elongated. After the lateral force is removed, the abutment returns to the original position, so the preload disappears, and the screw loosens [30, 32]. Accordingly, to prevent screw loosening, it is necessary to thicken the implant wall or place the implant-abutment connection in a deep position to redistribute stress [23, 33-34]. Generally, as the 
width of the alveolar bone is predetermined individually, the increase in the implant diameter is limited. In this limited circumference, the only way to prevent an implant wall flaring is to use a deep implant-abutment connection depth to maximize the stress distribution.

\subsection{Alveolar Bone Stimulation}

Long-term studies of the Brånemark abutment system (Nobel Biocare, USA) using the external hex connection showed that when the implant was first exposed to an oral cavity, a marginal bone loss around the implant of about 1 or $1.5 \mathrm{~mm}$ occurred during the first year $[35,36]$. Additionally, $0.2 \mathrm{~mm}$ of bone mass was absorbed every year, as revealed in a previous study [37]. Several studies have shown that the marginal bone mass around the internal friction connection, especially for the Astra Tech Implant system, is maintained as time passes [15, 36].

An intact soft tissue around the implant helps preserve a healthy environment [20]. When the mucosal seal formed around an implant is broken, microbes may penetrate the internal space and increase the likelihood of peri-implant diseases and bone resorption [38-41]. Mobility at the implant-abutment connection can destroy the mucosal seal due to the abutment screw loosening. This loosening often occurs in implants with an external hex connection, where the lateral force is concentrated on the abutment screw [42]. In the internal friction connection, the lateral force is distributed along with the implant-abutment interface, leading to less screw loosening with abutment immobility.

In natural teeth, periodontal ligaments transfer some stress to the alveolar bone for adequate stimulation, allowing the alveolar bone to be maintained in a healthy state. As with periodontal ligaments, when the implant stimulates around the alveolar bone appropriately, the peri-implant bone can be well-preserved. Harold M. Frost's theory can be applied to the alveolar bone as well as to other bones in the human body [43-44]; therefore, under proper strain conditions, osteoblasts can be activated, impacting the bone status. This concept was first applied to the implant systems with the internal conical friction connection with a slope of $11^{\circ}$, well-balanced with the implant wall thickness at the top to transfer the proper strain to the peri-implant bone. When the occlusal force is applied to the abutment, it is transferred through the implant wall to the alveolar bone as the strain for proper stimulation [45]. The mechanism of stimulation is that the abutment is sunk downward by occlusal force, causing the upper implant wall to flare and the peri-implant bone to stimulate appropriately. This stimulation prevents alveolar bone resorption and even induces growth.

\section{Micro-Thread}

\subsection{Role of Implant Thread}

Before the advent of the screw-shaped implant system, most of the implants were blade-shaped or cylindrical without threads. These implants showed very poor success rates with many complications and gradually disappeared $[46,47]$. The screw-shaped endosseous implant, originally developed by Dr. Brånemark, was the first system to demonstrate successful long-term and predictable clinical results. This screw-shaped implant has a thread on the implant surface by which the occlusal force is delivered around the alveolar bone as the favorable condition [46, 47]. There are three types of loads at the implant-bone interface: compressive, tensile, and shear stress [48]. 
Of the three loads, the compressive stress is the most beneficial load increasing the degree and strength of osseointegration [48]. In the plain-shaped implants, the occlusal force is transformed to shear stress, which is likely to destroy interface contact at the implant-alveolar bone interface. In contrast, the thread of the implant possibly transforms the shear stress into compressive stress, stimulating the bone around threads and producing a stable bone condition [20,49]. However, it is noteworthy that the surface parallel to the implant axis always causes shear stress, despite the presence of threads. According to Faegh et al., threads could cause various stress states along with the implant-bone interface but could not cause a reduction in shear stress [50]. Besides, implant thread shape affects the type of force at the implant-bone interface [49]. According to Bumgardner et al., the amount of shear force produced by the thread increased as the thread face angle increased [51]. Several studies have shown that the compressive stress intensity of the V-shape thread was lower than that of the square shape thread $[52,53]$.

Threads of the implant also improve stability by reducing the micromotion [54]. When an implant exhibits large micromotion, a large portion of the implant-bone interface is differentiated into a soft tissue, reducing the amount of bone tissue available for remodeling [55].

\subsection{Definition of Micro-Thread}

To develop an implant, thread depth, a critical factor, need to be considered. In the original Brannemark implant system, the thread depth was $0.375 \mathrm{~mm}$. Since then, a depth of approximately $0.3 \mathrm{~mm}$ has been regarded as standard and applied to many implants. Thereafter, various thread dimensions have been introduced.

The micro-thread was first introduced and employed by the Astra Tech Implant System. It is emphasized that definitions of micro-threads or macro-threads include the thread depth, although there have been no obvious criteria for dividing these two dimensions to date (see Figure 3). Astra Tech implants have macro-threads $(0.66 \mathrm{~mm}$ in pitch and $0.3 \mathrm{~mm}$ in depth) and micro-threads ( 0.22 $\mathrm{mm}$ in pitch and $0.1 \mathrm{~mm}$ in depth).

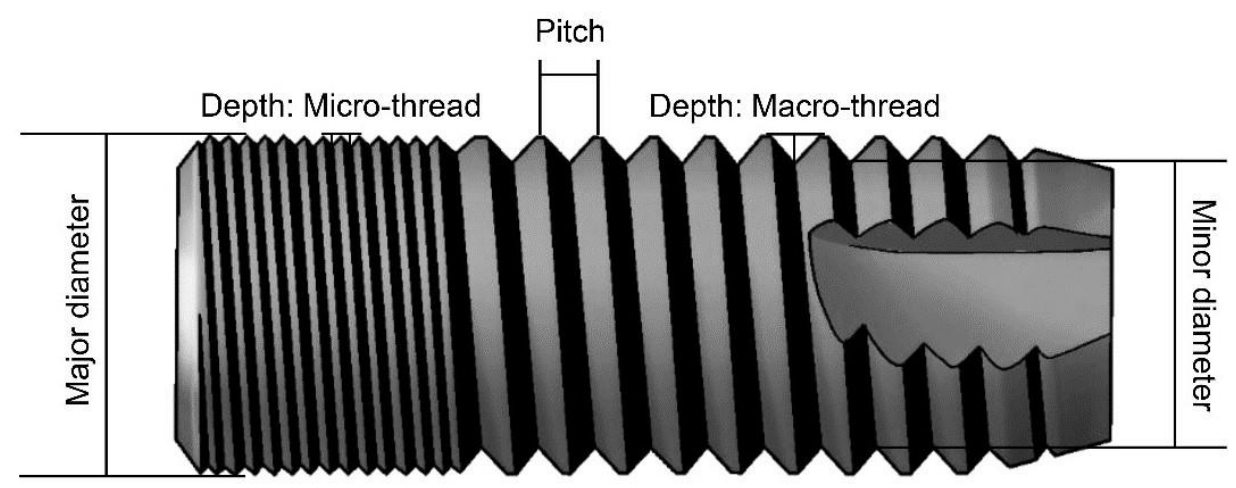

Figure 3 The definitions of thread depth and pitch. Notably, the difference between micro and macro-threads is thread depth. This figure also shows the major and minor diameters of a screw. It is notable that, in implantology, the implant diameter means the major diameter.

The definitions of macro and micro-threads are often confused with those of single and multiple threads. When an implant is turned once, the distance of vertical advancement parallel to the 
implant axis is defined as a lead. When one lead has the same value as the distance between adjacent threads, i.e., pitch, the implant is defined as a single-threaded implant. When a lead is equal to twice the pitch, this implant is double-threaded, and it belongs to the multiple-threaded category. For example, the micro-threads of the Astra Tech implants are triple-threaded because the threads have a lead $(0.66 \mathrm{~mm})$ equal to thrice the pitch $(0.22 \mathrm{~mm})$. Consequently, Astra Tech implants are characterized by triple micro-threads at the upper part and single macro-threads at the lower part.

\subsection{Characteristics of Micro-Thread}

Stig Hansson, the inventor of the original Astra Tech Implant System, reported the significance of the micro-threads. Thereafter, several studies exploring the advantages of the micro-threads have been performed [56]. Few studies have shown that the micro-threads were beneficial in maintaining marginal bone level [57-63].

The micro-threads have immense critical significance and clinical applications. First, the microthreads allow tightening and adequate implant wall thickness. The implant thread is developed by milling technique using a milling machine or a computer numerical control machine and related tools. As the micro-threads have low thread depth, the amount subtracted by milling is insignificant. As mentioned above, the width of the implant is limited by the predetermined individual osteotomy site. Therefore, the implant wall at the micro-threaded area is thicker than when this area is milled to become macro-threaded. The thick implant wall of the micro-threads allows a deep implantabutment connection without the loss of mechanical strength, guaranteeing a larger contact surface. Therefore, the external force, including the occlusal force, gets properly distributed. If the implant wall is thinned by forming the macro-thread, the implant-abutment connection depth would be shallowed to secure a proper thickness of the implant wall and become unstable. If the connection is deepened, the implant wall gets thinner; this may create many strength problems and cause disastrous clinical complications.

Second, the micro-threads convert shear stress to compressive stress more effectively by increasing the number of threads engaged in the bone [64]. The thread depth is closely associated with the pitch in terms of the number of threads engaged in the unit area or volume due to the bone response to a dimension [65]. When the thread depth is more, and the thread pitch is small, the alveolar bone is unable to grow into the space between the threads. Therefore, the pitch should be enhanced for alveolar bone growth for the deep threads, causing a decrease in the number of the engaged threads and the bone contact area. The pitch of micro-threads in an implant system is designed to be smaller than that of macro-threads, hinting at a larger number of micro threads included in a unit region than in macro-threads. Such an increase in the number of engaged threads is advantageous for converting the shear portion of the occlusal load to the compressive portion at the bone-implant interface. Furthermore, the occlusal force transmitted to one micro-thread is decreased when compared to that transmitted to a macro-thread. Consequently, the unit strain is applied to a thread, and the bone is optimally controlled in the micro-threaded implant system.

\section{Conclusions}

The internal conical friction connection structure and micro-threads have shown favorable biological hard tissue responses via their exceptional structural features such as the thickened 
implant wall, deepened implant-abutment connection, and an increased number of threads. These two designed structures make it possible to minimize clinical complications, including screw loosening, the fracture of implant components, and marginal bone loss. Dental clinicians must understand the internal conical friction connection and the micro-thread comprehensively.

Overall, this review highlights that the comprehension of these structures may help dental clinicians to select an appropriate implant system and to obtain the long-term predictability of implants inserted into their patients' mouths. This paper will prove useful to clinicians and researchers and may lead to better prosthetic devices with minimal complications.

\section{Acknowledgments}

This study was supported by grant no 04-2020-0105 from the Seoul National University Dental Hospital Research Fund.

\section{Author Contributions}

Writing-original draft preparation, K.-W.J. and J.C.K.; writing-review and editing, I.-S.L.Y.

\section{Funding}

Seoul National University Dental Hospital (No. 04-2020-0105).

\section{Competing Interests}

The authors have declared that no competing interests exist.

\section{References}

1. Afrashtehfar KI, Assery MK. Five considerations in cosmetic and esthetic dentistry. J N J Dent Assoc. 2014; 85: 14-15.

2. Feine JS, Carlsson GE, Awad MA, Chehade A, Duncan WJ, Gizani S, et al. The McGill consensus statement on overdentures. Mandibular two-implant overdentures as first choice standard of care for edentulous patients. Gerodontology. 2002; 19: 3-4.

3. Frost HM. Wolff's Law and bone's structural adaptations to mechanical usage: An overview for clinicians. Angle Orthod. 1994; 64: 175-188.

4. Goodacre CJ, Kan JY, Rungcharassaeng K. Clinical complications of osseointegrated implants. J Prosthet Dent. 1999; 81: 537-552.

5. Schwarz MS. Mechanical complications of dental implants. Clin Oral Implant Res. 2000; 11: 156158.

6. Afrashtehfar KI, Katsoulis J, Koka S, Igarashi K. Single versus splinted short implants at sinus augmented sites: A systematic review and meta-analysis. J Stomatol Oral Maxillofac Surg. 2020.

7. Vetromilla BM, Brondani LP, Pereira-Cenci T, Bergoli CD. Inlufence of different implantabutment connection designs on the mechanical and biological behavior of single-tooth implants in the maxillary esthetic zone: A systematic review. J Prosthet Dent. 2019; 121: 398403. 
8. Ceruso FM, Barnaba P, Mazzoleni S, Ottria L, Gargari M, Zuccon A, et al. Implant-abutment connections on single crowns: A systematic review. Oral Implantol. 2017; 10: 349-353.

9. Bozkaya $D$, Müftü S. Mechanics of the tapered interference fit in dental implants. J Biomech. 2003; 36: 1649-1658.

10. Mai HN, Lee KB, Lee DH. Fit of interim crowns fabricated using photopolymer-jetting 3D printing. J Prosthet Dent. 2017; 118: 208-215.

11. Koumjian JH, Nimmo A. Evaluation of fracture resistance of resins used for provisional restorations. J Prosthet Dent. 1990; 64: 654-657.

12. Sutter F, Weber HP, Sorensen J, Belser U. The new restorative concept of the ITI dental implant system: Design and engineering. Int J Periodont Rest Dent. 1993; 13: 409-431.

13. Muftu A, Chapman RJ. Replacing posterior teeth with freestanding implants: Four-year prosthodontic results of a prospective study. J Am Dent Assoc. 1998; 129: 1097-1102.

14. Palmer RM, Smith BJ, Palmer PJ, Floyd PD. A prospective study of Astra single tooth implants. Clin Oral Implant Res. 1997; 8: 173-179.

15. Palmer RM, Palmer PJ, Smith BJ. A 5-year prospective study of Astra single tooth implants. Clin Oral Implant Res. 2000; 11: 179-182.

16. Makkonen TA, Hoimberg S, Niemi L, Olsson C, Tammisalo T, Peltola J. A 5-year prospective clinical study of Astra Tech dental implants supporting fixed bridges or overdentures in the edentulous mandible. Clin Oral Implant Res. 1997; 8: 469-475.

17. Arvidson K, Bystedt H, Frykholm A, von Konow L, Lothigius E. A 3-year clinical study of Astra dental implants in the treatment of edentulous mandibles. Int J Oral Maxillofac Implant. 1992; 7: 321-329.

18. Arvidson K, Bystedt H, Frykholm A, von Konow L, Lothigius E. Five-year prospective follow-up report of the Astra Tech Dental Implant System in the treatment of edentulous mandibles. Clin Oral Implant Res. 1998; 9: 225-234.

19. Kim HY, Yang JY, Chung BY, Kim JC, Yeo IL. Peri-implant bone length changes and survival rates of implants penetrating the sinus membrane at the posterior maxilla in patients with limited vertical bone height. J Periodontal Implant Sci. 2013; 43: 58-63.

20. Kim JJ, Lee JH, Kim JC, Lee JB, Yeo IL. Biological responses to the transitional area of dental implants: Material- and structure-dependent responses of peri-implant tissue to abutments. Materials. 2019; 13: 72.

21. Bozkaya D, Muftu S, Muftu A. Evaluation of load transfer characteristics of five different implants in compact bone at different load levels by finite elements analysis. J Prosthet Dent. 2004; 92: 523-530.

22. Bozkaya D, Muftu S. Mechanics of the taper integrated screwed-in (TIS) abutments used in dental implants. J Biomech. 2005; 38: 87-97.

23. Lee JH, Huh YH, Park CJ, Cho LR. Effect of the coronal wall thickness of dental implants on the screw joint stability in the internal implant-abutment connection. Int J Oral Maxillofac Implant. 2016; 31: 1058-1065.

24. Hansson S. A conical implant-abutment interface at the level of the marginal bone improves the distribution of stresses in the supporting bone. An axisymmetric finite element analysis. Clin Oral Implant Res. 2003; 14: 286-293.

25. Hansson S. Implant-abutment interface: Biomechanical study of flat top versus conical. Clin Implant Dent Relat Res. 2000; 2: 33-41. 
26. Yilmaz B, Gilbert AB, Seidt JD, McGlumphy EA, Clelland NL. Displacement of implant abutments following initial and repeated torqueing. Int J Oral Maxillofac Implant. 2015; 30: 1011-1018.

27. Michalakis KX, Calvani PL, Muftu S, Pissiotis A, Hirayama H. The effect of different implantabutment connections on screw joint stability. J Oral Implant. 2014; 40: 146-152.

28. Saber FS, Abolfazli N, Ataei SJ, Motlagh MT, Gharekhani V. The effect of repeated torque tightening on total lengths of implant abutments in different internal implant-abutment connections. J Dent Res Dent Clin Dent Prospect. 2017; 11: 110-116.

29. Jeong CG, Kim SK, Lee JH, Kim JW, Yeo IL. Clinically available preload prediction based on a mechanical analysis. Arch Appl Mech. 2017; 87: 2003-2009.

30. Kim KS, Han JS, Lim YJ. Settling of abutments into implants and changes in removal torque in five different implant-abutment connections. Part 1: Cyclic loading. Int J Oral Maxillofac Implants 2014; 29: 1079-1084.

31. Siamos G, Winkler S, Boberick KG. Relationship between implant preload and screw loosening on implant-supported prostheses. J Oral Implantol. 2002; 28: 67-73.

32. Pintinha M, Camarini ET, Sábio S, Pereira JR. Effect of mechanical loading on the removal torque of different types of tapered connection abutments for dental implants. J Prosthet Dent. 2013; 110: 383-388.

33. Huang HM, Wu LD, Lee SY, Chen HC, Chen JL, Chen CT. Stress analysis of different wall thicknesses of implant fixture with various boundary levels. J Med Eng Technol. 2000; 24: 267272.

34. Pérez MA. Life prediction of different commercial dental implants as influence by uncertainties in their fatigue material properties and loading conditions. Comput Methods Programs Biomed. 2012; 108: 1277-1286.

35. De Medeiros RA, Pellizzer EP, Filho Vechiato AJ, Dos Santos DM, Da Silva EV, et al. Evaluation of marginal bone loss of dental implants with internal or external connections and its association with other variables: A systematic review. J Prosthet Dent. 2016; 116: 501-506.

36. Puchades-Roman L, Palmer RM, Palmer PJ, Howe LC, Ide M, Wilson RF. A Clinical, radiographic, and microbiologic comparison of Astra Tech and Brånemark single tooth implants. Clin Implant Dent Relat Res. 2000; 2: 78-84.

37. Albrektsson T, Zarb G, Worthington P, Eriksson AR. The long-term efficacy of currently used dental implants: A review and proposed criteria of success. Int J Oral Maxillofac Implant. 1986; 1: 11-25.

38. Abdallah MN, Badran Z, Ciobanu O, Hamdan N, Tamimi F. Strategies for optimizing the soft tissue seal around osseointegrated implants. Adv Healthc Mater. 2017; 6: 1700549.

39. Hermann JS, Buser D, Schenk RK, Cochran DL. Crestal bone changes around titanium implants. A histometric evaluation of unloaded non-submerged and submerged implants in the canine mandible. J Periodontol. 2000; 71: 1412-1424.

40. Hermann JS, Schoolfield JD, Schenk RK, Buser D, Cochran DL. Influence of the size of the microgap on crestal bone changes around titanium implants. A histometric evaluation of unloaded non-submerged implants in the canine mandible. J Periodontol. 2001; 72: 1372-1383.

41. Monje A, Insua A, Wang HL. Understanding peri-implantitis as a plaque-associated and sitespecific entity: On the local predisposing factors. J Clin Med. 2019; 8: 279. 
42. Gracis S, Michalakis K, Vigolo P, Von Steyern PV, Zwahlen M, Sailer I. Internal vs. external connections for abutments/reconstructions: A systematic review. Clin Oral Implant Res. 2012; 23: 202-216.

43. Frost HM. Perspectives: Bone's mechanical usage windows. Bone Miner. 1992; 19: 257-271.

44. Frost HM. A 2003 update of bone physiology and Wolff's Law for clinicians. Angle Orthod. 2004; 74: 3-15.

45. De Vasconcellos LG, Kojima AN, Nishioka R, Vasconcelos L, Balducci I. Axial loads on implantsupported partial fixed prostheses for external and internal hex connections and machined and plastic copings: Strain gauge analysis. J Oral Implantol. 2015; 41: 149-154.

46. Buser D, Sennerby L, De Bruyn H. Modern implant dentistry based on osseointegration: 50 years of progress, current trends and open questions. Periodontol. 2000. 2017; 73: 7-21.

47. Taylor TD, Agar JR. Twenty years of progress in implant prosthodontics. J Prosthet Dent. 2002; 88: 89-95.

48. Misch CE, Strong T, Bidez MW. Contemporary implant dentistry. 3rd ed. St Louis; CV Mosby, 2008. p.200-p.229.

49. Abuhussein H, Pagni G, Rebaudi A, Wang HL. The effect of thread pattern upon implant osseointegration. Clin Oral Implants Res. 2010; 21: 129-136.

50. Faegh S, Müftü S. Load transfer along the bone-dental implant interface. J Biomech. 2010; 43: 1761-1770.

51. Bumgardner JD, Boring JG, Cooper Jr RC, Gao C, Givaruangsawat S, Gilbert JA, et al. Preliminary evaluation of a new dental implant design in canine models. Implant Dent. 2000; 9: 252-260.

52. Geng JP, Ma QS, Xu W, Tan KB, Liu GR. Finite element analysis of four thread-form configurations in a stepped screw implant. J Oral Rehabil. 2004; 31: 233-239.

53. Eraslan $O$, Inan $O$. The effect of thread design on stress distribution in a solid screw implant: $A$ 3D finite element analysis. Clin Oral Investig. 2010; 14: 411-416.

54. Winter W, Klein D, Karl M. Micromotion of dental implants: Basic mechanical considerations. J Med Eng. 2013; 2013: 265412.

55. Irandoust S, Müftü S. The interplay between bone healing and remodeling around dental implants. Sci Rep. 2020; 10: 4335.

56. Hansson S. The implant neck: Smooth or provided with retention elements. A biomechanical approach. Clin Oral Implant Res. 1999; 10: 394-405.

57. Lee DW, Choi YS, Park KH, Kim CS, Moon IS. Effect of microthread on the maintenance of marginal bone level: A 3-year prospective study. Clin Oral Implants Res. 2007; 18: 465-470.

58. Song DW, Lee DW, Kim CK, Park KH, Moon IS. Comparative analysis of peri-implant marginal bone loss based on microthread location: A 1-year prospective study after loading. J Periodontol. 2009; 80: 1937-1944.

59. Bratu EA, Tandlich M, Shapira L. A rough surface implant neck with microthreads reduces the amount of marginal bone loss: A prospective clinical study. Clin Oral Implants Res. 2009; 20: 827-832.

60. Lee SY, Piao CM, Koak JY, Kim SK, Kim YS, Ku Y, Rhyu IC, Han CH, Heo SJ. A 3-year prospective radiographic evaluation of marginal bone level around different implant systems. J Oral Rehabil. 2010; 37: 538-544.

61. Calvo-Guirado JL, López-López PJ, Martínez Pérez-Albacete C, Javed F, Granero-Marín JM, Maté Sánchez de Val JE, et al. Peri-implant bone loss clinical and radiographic evaluation around 
rough neck and microthread implants: A 5-year study. Clin Oral Implants Res. 2018; 29: 635643.

62. Al-Thobity AM, Kutkut A, Almas K. Microthreaded implants and crestal bone loss: A systematic review. J Oral Implantol. 2017; 43: 157-166.

63. Niu W, Wang P, Zhu S, Liu Z, Ji P. Marginal bone loss around dental implants with and without microthreads in the neck: A systematic review and meta-analysis. J Prosthet Dent. 2017; 117: 34-40.

64. Hudieb MI, Wakabayashi N, Kasugai S. Magnitude and direction of mechanical stress at the osseointegrated interface of the microthread implant. J Periodontol. 2011; 82: 1061-1070.

65. Albrektsson T. Healing of bone grafts: In vivo studies of tissue reactions at autografting of bone in the rabbit tibia. Gothenburg: University of Gothenburg; 1979.

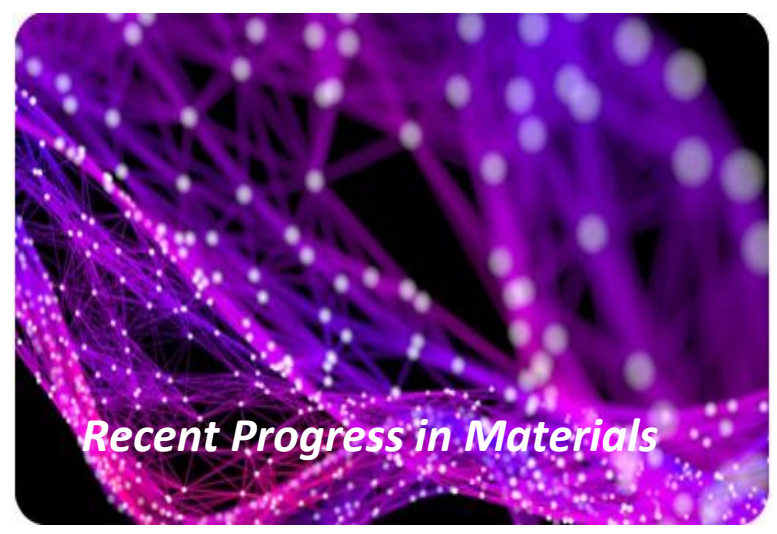

Enjoy Recent Progress in Materials by:

1. Submitting a manuscript

2. Joining in volunteer reviewer bank

3. Joining Editorial Board

4. Guest editing a special issue

For more details, please visit:

http://www.lidsen.com/journals/rpm 